\title{
Effect of Cilostazol Treatment on Adiponectin and Soluble CD40 Ligand Levels in Diabetic Patients With Peripheral Arterial Occlusion Disease
}

\author{
Ching-Jung Hsieh, MD; Pei-Wen Wang, MD
}

\begin{abstract}
Background: Peripheral arterial occlusion disease (PAOD) is caused mainly by chronic inflammation and endothelium dysfunction, and is often treated with cilostazol. However, because this drug's influence on atherogenic cytokines is still not well known, this study examined the effect of cilostazol on the serum levels of soluble CD40 ligand (sCD40L), adiponectin and high-sensitivity C-reactive protein (hs-CRP) in patients with type 2 diabetes and PAOD.

Methods and Results: The 92 type 2 diabetics with PAOD and 100 non-PAOD diabetics were enrolled and randomly assigned to a group receiving either cilostazol or placebo for 6 months. The atherogenic cytokines were measured at the beginning and completion of the study. In the PAOD groups, those in the cilostazol group had significant changes in the levels of hs-CRP, sCD40L and adiponectin ( $\mathrm{P}=0.001, \mathrm{P}=0.05, \mathrm{P}=0.004$, respectively). Changes in the levels of adiponectin and $\mathrm{sCD} 40 \mathrm{~L}$ were more significant in the PAOD group treated with cilostazol than in the non-PAOD group also treated with the $\operatorname{drug}(\mathrm{P}=0.01$ and $\mathrm{P}=0.008$, respectively).

Conclusions: Cilostazol can decrease hs-CPR and sCD40L levels and increase that of adiponectin, and then delay the progression of atherogenesis and chronic inflammation in type 2 diabetics, especially those with PAOD. (Circ J 2009; 73: 948-954)
\end{abstract}

Key Words: Adiponectin; CD40; Cilostazol; Diabetes mellitus; Peripheral arterial disease

$\mathbf{P}$ eripheral arterial occlusion disease (PAOD) is a common manifestation of atherosclerosis in patients with type 2 diabetes mellitus (DM)!,2 In Taiwan, approximately $33-50 \%$ of patients undergoing lower extremity amputation have DM, and more than $50 \%$ of them have PAOD, 3,4 The risk factors associated with PAOD are similar to those for coronary artery disease and cerebrovascular disease.

It has been proved that atherosclerosis-related macroangiopathy is a result of chronic inflammation and endothelium dysfunction. Levels of high-sensitivity C-reactive protein (hs-CRP) and adiponectin have been found to be markers of chronic inflammation in many human studies ${ }^{5-7}$ Interaction of the multipotent immunomodulator CD40 ligand with its receptor is also as an important contributor to chronic inflammation and endothelium dysfunction. The soluble form of the CD40 ligand (sCD40L), a marker of proinflammatory and platelet activation, is high in the sera of DM patients with coronary artery disease? However, few studies have investigated the relationships between PAOD and adiponectin and sCD40L levels.

(Received September 24, 2008; revised manuscript received November 26, 2008; accepted December 15, 2008; released online March 12, 2009)

Division of Endocrinology and Metabolism, Department of Internal Medicine, Chang Gung Memorial Hospital-Kaohsiung Medical Center, Chang Gung University College of Medicine, Kaohsiung, Taiwan Mailing address: Ching-Jung Hsieh, MD, Department of Internal Medicine, Chang Gung Memorial Hospital, 123, Ta-Pei Road, Niao-Sung Hsiang, Kaohsiung Hsien 83305, Taiwan. E-mail: c2607c@ms56. hinet.net

All rights are reserved to the Japanese Circulation Society. For permissions, please e-mail: cj@j-circ.or.jp
Cilostazol, a vasodilator and inhibitor of platelet aggregation, has been used in the treatment of chronic PAOD since 1988. Because little is known regarding its effects on PAOD and the aforementioned atherogenic cytokines in DM patients, we performed a randomized, placebo-controlled, single-blinded trial to examine the effect of cilostazol treatment on the serum levels of sCD-40L, adiponectin and hs-CRP in patients with type $2 \mathrm{DM}$.

Methods
Subjects
We enrolled 92 PAOD patients ( 53 women, 39 men;
mean age $63.3 \pm 18.8$ years) and 100 non-PAOD patients a
controls ( 58 women, 42 men; mean age $63.0 \pm 14.7$ years) at
our outpatient clinic from 2006 to 2008 . Sex ratio and
ranges of age and body mass index (BMI) were considered
while selecting the controls. All patients were confirmed
to have type 2 DM based on the 2005 American Diabetes
Association diagnostic criteria and had received oral anti-
diabetic drugs (OADs) for more than 6 months. Because
some antiplatelet, antihypertension and antihyperlipidemia
drugs have an antiinflammatory effect, the dosages of all
medications, including OADs, aspirin, antihypertension
drugs and antihyperlipidemia drugs, were not changed for
6 months prior to the study or during the study period. We
excluded any patient who had received insulin injections
for more than 1 month or had been found to have had car-
diogenic shock, unstable angina, old stroke, or myocardial
infarction during the preceding 6 months, had an ankle sys-
tolic blood pressure (SBP) $\geq 200$ mmHg, had been treated
with insulin, and had impaired renal function (creatinine
level $>1.4$ mg/dl), cancer, systemic inflammatory disease or


Table 1. Characteristics of the Control and Patient Groups

\begin{tabular}{|c|c|c|c|}
\hline & PAOD group & Non-PAOD group & $\mathrm{P}$ value \\
\hline Age (years) & $63.3 \pm 18.8$ & $63.0 \pm 14.7$ & NS \\
\hline $\operatorname{Sex}(M / F)$ & $39 / 53$ & $42 / 58$ & NS \\
\hline BMI $\left(\mathrm{kg} / \mathrm{m}^{2}\right)$ & $26.0 \pm 4.5$ & $25.9 \pm 3.9$ & NS \\
\hline $\mathrm{WC}(\mathrm{cm})$ & $98.7 \pm 11.9$ & $98.4 \pm 10.0$ & NS \\
\hline $\mathrm{BF}(\%)$ & $27.1 \pm 5.9$ & $26.8 \pm 6.5$ & NS \\
\hline SBP (mmHg) & $124 \pm 22.5$ & $127 \pm 23.8$ & NS \\
\hline $\mathrm{DBP}(\mathrm{mmHg})$ & $74 \pm 12.4$ & $72 \pm 10.9$ & NS \\
\hline $\mathrm{TC}(\mathrm{mg} / \mathrm{dl})$ & $188.3 \pm 35.8$ & $185 \pm 50.9$ & NS \\
\hline $\operatorname{LDL}(\mathrm{mg} / \mathrm{dl})$ & $119.9 \pm 29.4$ & $115 \pm 33.7$ & NS \\
\hline $\mathrm{HDL}(\mathrm{mg} / \mathrm{dl})$ & $49.4 \pm 13.5$ & $50.1 \pm 14.0$ & NS \\
\hline $\mathrm{TG}(\mathrm{mg} / \mathrm{dl})$ & $147.6 \pm 82.0$ & $151 \pm 56.4$ & NS \\
\hline $\mathrm{HbAlc}_{1 \%}(\%)$ & $8.6 \pm 2.1$ & $8.2 \pm 1.1$ & 0.06 \\
\hline HOMA IR & $4.22 \pm 1.21$ & $3.98 \pm 1.19$ & NS \\
\hline hs-CRP (ng/ml) & $7.2 \pm 4.5$ & $2.5 \pm 1.5$ & $<0.001$ \\
\hline Adiponectin $(\mu \mathrm{g} / \mathrm{ml})$ & $7.8 \pm 5.8$ & $9.1 \pm 2.9$ & $<0.001$ \\
\hline sCD40L (ng/ml) & $8.6 \pm 4.9$ & $8.1 \pm 3.1$ & 0.01 \\
\hline ABI (right leg) & $0.76 \pm 0.11$ & $1.15 \pm 0.13$ & $<0.001$ \\
\hline ABI (left leg) & $0.69 \pm 0.18$ & $1.16 \pm 0.09$ & $<0.001$ \\
\hline \multicolumn{4}{|l|}{ Comorbidity } \\
\hline Hypertension (\%) & 36.5 & 38.0 & NS \\
\hline Hyperlipidemia (\%) & 40.6 & 38.0 & NS \\
\hline \multicolumn{4}{|l|}{ Drugs } \\
\hline Antihypertensive & 34.4 & 35.0 & NS \\
\hline Antiplatelet & 65.6 & 63 & NS \\
\hline Lipid-lowering & 40.6 & 38 & NS \\
\hline
\end{tabular}

PAOD, peripheral arterial occlusion disease; BMI, body mass index; WC, waist circumference; BF, body fat; SBP, systolic blood pressure; DBP, diastolic blood pressure; TC, total cholesterol; LDL, low-density lipoprotein; HDL, high-density lipoprotein; TG, triglyceride; HbAlc, hemoglobin Alc; HOMA IR, homeostasis model assessment insulin resistance; hs-CRP, high-sensitive C-reactive protein; sCD40L, soluble CD40 ligand; ABI, ankle-brachial index.

had ever been treated with cilostazol. We also excluded anyone who had a history of smoking or had undergone leg surgery.

PAOD was defined as ankle-brachial index $(\mathrm{ABI})<0.9$ in either leg, as described in previous studies of PAOD patients with type $2 \mathrm{DM} 3,4$ The diabetic patients with PAOD and those without PAOD were randomly assigned to a 6-month treatment group receiving either cilostazol $(100 \mathrm{mg}$ twice daily) or placebo. The study was conducted according to the guidelines of the Declaration of Helsinki, and the study protocol was approved by the Ethics Committee of the Chang Gung Memorial Hospital. Written informed consent was given by all subjects prior to their participation.

After resting at least $30 \mathrm{~min}$ while supine on a bed, ABI measurements were performed in a room maintained at a temperature of $23-25^{\circ} \mathrm{C}$. The ABI was calculated as the ratio of ankle SBP to the brachial SBP, both of which were measured by an automatic device (form PWV/ABI; AT, Komaki, Aichi, Japan).

The following clinical and laboratory parameters were measured at the beginning and completion of the study: BMI, blood pressure (BP) waist circumference (WC), \% body fat (\%BF), ABI and the serum levels of total cholesterol (TC), low-density lipoprotein (LDL), high-density lipoprotein (HDL), triglycerides (TG), hemoglobin Alc (HbAlc), fasting blood glucose (FBG), insulin, hs-CRP, adiponectin and sCD40L. The blood samples from each patient were obtained after an overnight fast that began at midnight. Patients were requested to wear light clothing during the measurements of weight, height, and BMI. The \%BF was measured by electrical bioimpedance (BioDynamic Model 310 Body Composition Analyzer: Seattle, WA, USA) after a 4-h fast. The serum samples for hs-CRP, sCD40L and adiponectin levels were frozen at $-70^{\circ} \mathrm{C}$ until used. All samples from the same patient were run in the same assay and every sample was measured 3 times to obtain an average value.

\section{Assays}

The concentrations of FBG, TC, LDL, HDL and TG were measured using an autoanalyser (Hitachi 7250 Special; Hitachi, Tokyo, Japan). The HbA1c level was measured by high-pressure liquid chromatography (Bio-Rad Laboratories, Richmond, CA, USA), and the plasma hs-CRP level was measured by a high-sensitivity monoclonal antibody assay (Dade Behring Marburg GmbH, Germany).

Plasma insulin concentrations were determined by automated immunoassay (Access; Beckman Instruments, Fullerton, CA, USA). Insulin resistance (IR) was determined by homeostasis model assessment (HOMA) and calculated using the FBG and fasting insulin levels in each participant:

HOMA IR = fasting glucose $(\mathrm{mmol} / \mathrm{L}) \times$ fasting insulin $(\mathrm{mU} / \mathrm{ml}) / 22.5$.

The fasting serum adiponectin concentration was measured using a commercially available ELISA kit (Human Adiponectin ELISA kit, Linco Research, MO, USA). The level of circulating SCD40L was also determined by ELISA kit (Bender Med Systems, Vienna, Austria).

\section{Statistical Analysis}

Differences between groups were analyzed using a nonparametric Wilcoxon test. The relationships between variables were analyzed by Pearson correlation and stepwise multiple regression analyses. Differences between time points in treatment were calculated using repeated measures of general linear model. All data are reported as mean \pm SD. A probability value $<0.05$ was regarded as significant. All 
a Correlation between $\mathrm{ABI}$ and hs-CRP

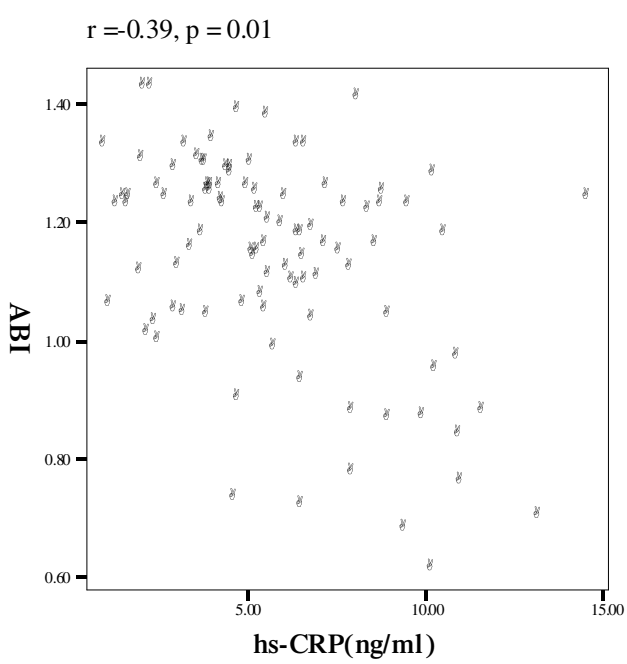

b Correlation between $\mathrm{ABI}$ and adiponectin $\mathrm{r}=0.31, \mathrm{p}<0.001$

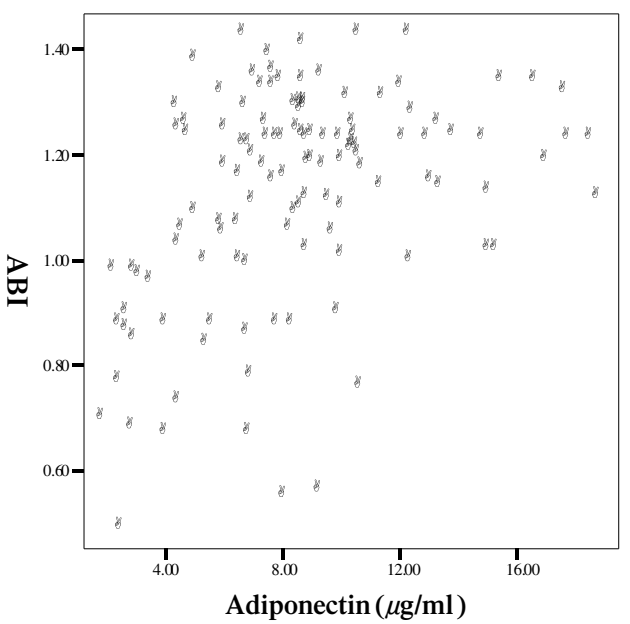

C Correlation between $\mathrm{ABI}$ and $\mathrm{SCD} 40 \mathrm{~L}$ $\mathrm{r}=-0.40, \mathrm{p}=0.007$

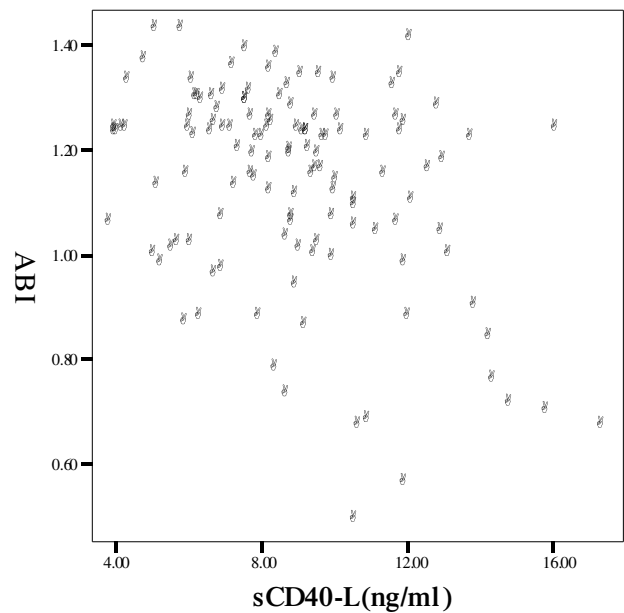

Figure. Correlation between ankle-brachial index (ABI) and chronic inflammation markers: high-sensitivity C-reactive protein (CRP), adiponectin and soluble CD40 ligand.

statistical operations were performed using the Statistical Package for Social Science program (SPSS for Windows, Version 11.5; SPSS, Chicago, IL, USA).

\section{Results}

\section{PAOD and Non-PAOD Patients}

Table 1 compares the different parameters between PAOD and non-PAOD patients. Although the 2 groups were similar in age, sex ratio, $\mathrm{BP}, \mathrm{BMI}, \mathrm{WC}, \% \mathrm{BF}$ and similar serum levels of TC, LDL, HDL, TG, HOMA IR and $\mathrm{HbA1c}$, the PAOD group had higher serum levels of hs-CRP and $\mathrm{SCD} 40 \mathrm{~L}$ and a lower adiponectin level and $\mathrm{ABI}$ than the non-PAOD group.

\section{Correlation Between ABI and Other Parameters}

In all patients, ABI negatively correlated with age and the levels of hs-CRP and SCD40L $(r=-0.79, \mathrm{P}<0.001 ; \mathrm{r}=-$ $0.39, \mathrm{P}=0.01 ; \mathrm{r}=-0.40, \mathrm{P}=0.007$, respectively) and positively correlated with adiponectin level $(\mathrm{r}=0.311, \mathrm{P}<0.001)$
(Figure). There was no apparent correlation between ABI and the other parameters, including $\mathrm{BMI}, \% \mathrm{BF}, \mathrm{BP}$ or $\mathrm{WC}$ or levels of TC, LDL, HDL, TG, HOMA IR or HbA1c. We used linear regression analysis to predict the effect of each of the measured parameters on ABI in PAOD patients (Table 2). Our multivariate regression analysis, which was performed using generalized estimating equations, revealed that age and adiponectin levels were significantly strong predictors for $\mathrm{ABI}(\mathrm{P}<0.0001$ and $\mathrm{P}=0.023$, respectively).

\section{Changes in the Tested Parameters After Cilostazol Treatment}

Table 3 presents the changes in the tested parameters in the PAOD group after 6 months of treatment with cilostazol, and in the PAOD group after 6 months of treatment with placebo. In the PAOD groups treated with cilostazol, there were no significant changes in ABI, BMI, WC, or \%BF or the levels of TC, LDL, HDL, TG, HOMA IR or $\mathrm{HbAl}_{1}$ (tests of within-subjects contrasts, $\mathrm{P}>0.05$ ). However, there were significant changes in the levels of 
Table 2. Multiple Regression Analysis of the Relationships Among Age, BMI, \% BF, WC and the Levels of HbA1c, TC, LDL, HDL, TG, hs-CRP, Adiponectin and SCD40L

\begin{tabular}{lcccc}
\hline & $\begin{array}{c}\text { Regression } \\
\text { coefficient }\end{array}$ & SE & $\begin{array}{c}\text { Standardized } \\
\text { regression coefficient }\end{array}$ & P value \\
\hline Age & 0.397 & 0.34 & -0.38 & $<0.0001$ \\
Adiponectin & 0.157 & 0.18 & 0.11 & 0.023 \\
\hline
\end{tabular}

Dependent variable: $\mathrm{ABI}$. $\mathrm{R}^{2}$ for the entire model $=0.54$.

Independent variables: age, BMI, \%BF, WC HOMA IR and levels of HbAlc, TC, LDL, HDL, TG, hs-CRP, adiponectin and SCD40L.

See Table 1 for abbreviations.

Table 3. Effect of Cilostazol in PAOD Patients

\begin{tabular}{|c|c|c|c|c|c|c|}
\hline & \multicolumn{2}{|c|}{ Cilostazol group } & \multicolumn{2}{|c|}{ Placebo group } & \multirow{2}{*}{$P$ value } & \multirow{2}{*}{$\mathrm{P} *$ value } \\
\hline & Before treatment & After treatment & Before treatment & After treatment & & \\
\hline Age (years) & $62.6 \pm 9.5$ & & $63.8 \pm 9.4$ & & & NS \\
\hline $\operatorname{Sex}(M / F)$ & $19 / 22$ & & $20 / 21$ & & & NS \\
\hline BMI $\left(\mathrm{kg} / \mathrm{m}^{2}\right)$ & $26.2 \pm 5.5$ & $26.1 \pm 3.3$ & $25.8 \pm 4.1$ & $26.3 \pm 4.4$ & NS & NS \\
\hline $\mathrm{WC}(\mathrm{cm})$ & $98.2 \pm 12.2$ & $98.2 \pm 9.6$ & $99.2 \pm 9.9$ & $97.2 \pm 9.8$ & NS & NS \\
\hline $\mathrm{BF}(\%)$ & $27.3 \pm 5.9$ & $27.8 \pm 6.5$ & $27.0 \pm 5.3$ & $27.3 \pm 7.2$ & NS & NS \\
\hline $\mathrm{TC}(\mathrm{mg} / \mathrm{dl})$ & $190.1 \pm 29.4$ & $188.8 \pm 35.8$ & $186.5 \pm 35.8$ & $189.9 \pm 41.0$ & NS & 0.02 \\
\hline $\operatorname{LDL}(\mathrm{mg} / \mathrm{dl})$ & $119.8 \pm 30.4$ & $108.7 \pm 33.8$ & $120.0 \pm 28.4$ & $119.0 \pm 32.9$ & NS & 0.04 \\
\hline $\operatorname{HDL}(\mathrm{mg} / \mathrm{dl})$ & $48.3 \pm 12.1$ & $51.3 \pm 11.6$ & $50.5 \pm 13.0$ & $49.2 \pm 12.2$ & NS & NS \\
\hline $\mathrm{TG}(\mathrm{mg} / \mathrm{dl})$ & $146.2 \pm 89.5$ & $145.8 \pm 65.1$ & $147.6 \pm 82.0$ & $142.6 \pm 55.6$ & NS & NS \\
\hline $\mathrm{HbAlc}_{1 \mathrm{c}}(\%)$ & $8.8 \pm 2.1$ & $8.4 \pm 1.8$ & $8.4 \pm 1.6$ & $8.0 \pm 1.6$ & NS & NS \\
\hline HOMA IR & $4.12 \pm 1.33$ & $4.00 \pm 1.56$ & $4.31 \pm 1.45$ & $4.19 \pm 1.00$ & NS & NS \\
\hline hs-CRP (ng/ml) & $7.1 \pm 4.5$ & $4.6 \pm 3.1$ & $7.2 \pm 4.0$ & $8.9 \pm 4.9$ & $<0.001$ & 0.001 \\
\hline Adiponectin $(\mu \mathrm{g} / \mathrm{ml})$ & $8.1 \pm 5.8$ & $9.9 \pm 6.2$ & $7.4 \pm 5.1$ & $6.1 \pm 4.4$ & $<0.001$ & 0.004 \\
\hline $\mathrm{sCD} 40 \mathrm{~L}(\mathrm{ng} / \mathrm{ml})$ & $8.8 \pm 4.9$ & $4.8 \pm 4.8$ & $8.4 \pm 2.9$ & $10.9 \pm 1.8$ & 0.03 & 0.05 \\
\hline $\mathrm{ABI}$ (right leg) & $0.77 \pm 0.12$ & $0.76 \pm 0.18$ & $0.73 \pm 0.08$ & $0.78 \pm 0.10$ & NS & NS \\
\hline ABI (left leg) & $0.69 \pm 0.17$ & $0.71 \pm 0.17$ & $0.67 \pm 0.19$ & $0.66 \pm 0.11$ & NS & NS \\
\hline
\end{tabular}

Differences between the treatment time points were calculated using repeated measures of general linear model.

$\mathrm{P}$, tests of within-subjects contrasts in the group after 6 months of treatment with cilostazol; $\mathrm{P}^{*}$, tests of between-subjects effects. See Table 1 for abbreviations.

Table 4. Effect of Cilostazol in Non-PAOD Patients

\begin{tabular}{|c|c|c|c|c|c|c|}
\hline & \multicolumn{2}{|c|}{ Cilostazol group } & \multicolumn{2}{|c|}{ Placebo group } & \multirow{2}{*}{$P$ value } & \multirow{2}{*}{$\mathrm{P}^{*}$ value } \\
\hline & Before treatment & After treatment & Before treatment & After treatment & & \\
\hline Age (years) & $62.5 \pm 10.3$ & & $63.3 \pm 10.9$ & & & NS \\
\hline $\operatorname{Sex}(M / F)$ & $21 / 29$ & & $21 / 29$ & & & NS \\
\hline BMI $\left(\mathrm{kg} / \mathrm{m}^{2}\right)$ & $26.1 \pm 2.3$ & $26.4 \pm 3.3$ & $25.8 \pm 3.1$ & $26.4 \pm 5.2$ & NS & NS \\
\hline $\mathrm{WC}(\mathrm{cm})$ & $99.2 \pm 11.6$ & $100.2 \pm 9.6$ & $97.2 \pm 10.9$ & $97.2 \pm 9.8$ & NS & NS \\
\hline $\mathrm{BF}(\%)$ & $27.0 \pm 4.9$ & $27.4 \pm 6.6$ & $27.0 \pm 6.3$ & $27.6 \pm 6.2$ & NS & NS \\
\hline $\mathrm{TC}(\mathrm{mg} / \mathrm{dl})$ & $184.1 \pm 23.4$ & $188.8 \pm 35.8$ & $186.5 \pm 33.3$ & $189.9 \pm 32.1$ & NS & NS \\
\hline $\operatorname{LDL}(\mathrm{mg} / \mathrm{dl})$ & $119.8 \pm 30.4$ & $118.7 \pm 31.8$ & $112.0 \pm 38.3$ & $115.0 \pm 32.9$ & NS & NS \\
\hline $\operatorname{HDL}(\mathrm{mg} / \mathrm{dl})$ & $49.3 \pm 14.9$ & $51.3 \pm 11.6$ & $50.5 \pm 12.6$ & $50.2 \pm 12.7$ & NS & NS \\
\hline $\mathrm{TG}(\mathrm{mg} / \mathrm{dl})$ & $155.7 \pm 73.5$ & $145.8 \pm 65.1$ & $147.6 \pm 83.3$ & $142.6 \pm 55.6$ & NS & NS \\
\hline $\mathrm{HbAlc}(\%)$ & $8.1 \pm 2.3$ & $8.4 \pm 1.4$ & $8.2 \pm 1.0$ & $8.4 \pm 1.5$ & NS & NS \\
\hline HOMA IR & $3.92 \pm 1.41$ & $3.87 \pm 1.77$ & $4.03 \pm 2.10$ & $4.00 \pm 1.98$ & NS & NS \\
\hline hs-CRP (ng/ml) & $2.7 \pm 1.5$ & $2.1 \pm 3.1$ & $2.4 \pm 1.0$ & $2.9 \pm 4.9$ & 0.02 & 0.02 \\
\hline Adiponectin $(\mu \mathrm{g} / \mathrm{ml})$ & $9.0 \pm 3.7$ & $9.9 \pm 6.2$ & $9.1 \pm 5.3$ & $8.6 \pm 3.0$ & 0.03 & 0.04 \\
\hline $\mathrm{sCD} 40 \mathrm{~L}(\mathrm{ng} / \mathrm{ml})$ & $8.0 \pm 3.7$ & $8.3 \pm 4.5$ & $8.1 \pm 2.9$ & $8.3 \pm 1.8$ & NS & NS \\
\hline $\mathrm{ABI}$ (right leg) & $1.15 \pm 0.14$ & $1.16 \pm 0.23$ & $1.13 \pm 0.28$ & $1.15 \pm 0.18$ & NS & NS \\
\hline ABI (left leg) & $1.17 \pm 0.33$ & $1.17 \pm 0.37$ & $1.15 \pm 0.19$ & $1.16 \pm 0.21$ & NS & NS \\
\hline
\end{tabular}

Differences between the treatment time points were calculated using repeated measures of general linear model.

$\mathrm{P}$, tests of within-subjects contrasts in the group after 6 months of treatment with cilostazol; $\mathrm{P}^{*}$, tests of between-subjects effects.

See Table 1 for abbreviations.

hs-CRP, adiponectin and SCD40L ( $7.1 \pm 4.5$ vs $4.6 \pm 3.1 \mathrm{ng} / \mathrm{ml}$; $8.1 \pm 5.8$ vs $9.9 \pm 6.2 \mu \mathrm{g} / \mathrm{ml} ; 8.8 \pm 4.9$ vs $4.8 \pm 4.8 \mathrm{ng} / \mathrm{ml}$ tests of within-subjects contrasts, $\mathrm{P}<0.001, \mathrm{P}<0.001$ and $\mathrm{P}=0.03$, respectively). Comparing the effects of cilostazol and placebo, we found that patients in the cilostazol group had greater decreases in the levels of TC $(190.1 \pm 29.4$ vs $188.8 \pm$ $35.8 \mathrm{mg} / \mathrm{dl})$ and LDL $(119.8 \pm 30.4$ vs $108.7 \pm 33.8 \mathrm{mg} / \mathrm{dl})$ and greater decreases in the levels of hs-CRP and sCD40L than those in the placebo group (tests of between-subjects effects, $\mathrm{P}=0.02, \mathrm{P}=0.04, \mathrm{P}=0.001, \mathrm{P}=0.05$, respectively). Adiponectin levels were more clearly elevated after 6 months of cilostazol (tests of between-subjects effects, $\mathrm{P}=0.004$ ).

In the non-PAOD group (Table 4), the changes in the serum levels of hs-CRP and adiponectin were significant 
after 6 months of cilostazol $(2.7 \pm 1.5$ vs $2.1 \pm 3.1 \mathrm{ng} / \mathrm{ml} ; 9.0 \pm$ 3.7 vs $9.9 \pm 6.2 \mu \mathrm{g} / \mathrm{ml}$ tests of within-subjects contrasts; $\mathrm{P}=$ 0.02 and $\mathrm{P}=0.03$, respectively). However, the changes in ABI, BMI, WC, \%BF and in the levels of TC, LDL, HDL, TG, HOMA IR, HbA1c and sCD40L were not significant. Comparisons of the effect of cilostazol and placebo on outcome measures revealed that there was a more clear decrease in the serum levels of hs-CRP and increase in adiponectin after 6 months in the group treated with cilostazol than in those treated with the placebo (tests of betweensubjects effects, $\mathrm{P}=0.02, \mathrm{P}=0.04$, respectively).

\section{Comparison of Changes in the Parameters of the PAOD and Non-PAOD Groups After Cilostazol Therapy}

The changes in the serum levels of adiponectin and sCD40L were more apparent in the PAOD group than in the non-PAOD group (tests of between-subjects effects, $\mathrm{P}=0.01$ and $\mathrm{P}=0.008$, respectively).

\section{Discussion}

PAOD affects $29 \%$ of all DM patients aged $\geq 50$ years in the United States, and in Taiwan, approximately $10 \%$ of all type 2 DM patients aged $\geq 50$ years develop PAOD $^{3}$ and are also at a high risk of lower-extremity amputation. Chronic inflammation plays an important role in the acceleration of atherosclerosis in DM? The inflammatory marker, hs-CRP, is strongly associated with the development of PAOD 10,11 Adiponectin secreted by adipose cells might regulate nitric oxide and reduce the expression of adhesion molecules in endothelial cells. Several studies have shown that human adiponectin has antidiabetic and antiatherogenic properties, so it is an antiinflammatory marker and may be associated with PAOD! 12,13 CD40L can activate platelets to form a fresh thrombus and contribute to endothelium dysfunction and inflammation; sCD40L is released from activated platelets within minutes to hours after their activation! ${ }^{14}$ Previous studies have reported that individuals with type 1 or type 2 DM have elevated levels of plasma sCD40L 15 especially those who also have coronary artery disease ${ }^{16}$ In a previous study, circulating levels of CD40 ligand were elevated only in patients with more advanced symptomatic PAOD, but not in type $2 \mathrm{DM}$ patients ${ }^{17}$ In the present study, the ABI was significantly correlated with these pro-inflammatory markers. Our linear regression analyses, which we performed to identify the predictors of PAOD, also revealed the adiponectin level to be 1 of the best predictors of the ABI, besides age.

Cilostazol is able to elevate cyclic AMP levels by inhibiting cyclic nucleotide PDE3 activity and inhibiting platelet aggregation in response to ADP, collagen, epinephrine and arachidonic acid, and has long been used in the treatment of chronic PAOD. A previous report revealed that this drug reduces atherosclerosis by inhibiting superoxide TNF- $\alpha$ and activating endothelial nitric oxide synthase ${ }^{18}$ A short-term study also showed that cilostazol could reduce $23.6 \%$ of the serum level of hs-CRP in type $2 \mathrm{DM}$ patients, although no mention was made of PAOD ${ }^{19}$ This improvement probably occurs as a result of the activation of endothelial nitric oxide synthase ${ }^{20,21}$ Cilostazol can also stimulate differentiation of fibroblasts into adipocytes and stimulate PPAR-gamma transcription, which may contribute to the increased serum adiponectin levels $2^{2}$ In this study, cilostazol treatment alleviated chronic inflammation (high hs-CRP and low adiponectin) in both groups of DM patients; the increase in adiponectin was more apparent in the PAOD group.

Cilostazol has antiplatelet and antithrombotic effects. The mechanism of preventing neointimal formation is unclear, but cilostazol may inhibit intima formation, possibly through its inhibition of angiotensin II-forming enzymes or its effect on lipids (15\% reduction in plasma TG level and $10 \%$ increase in HDL level) $2^{23-25}$ In type 2 DM patients, cilostazol improves the post-prandial lipemia. ${ }^{26}$ Nomura et al demonstrated decreases in the plasma concentrations of soluble adhesion molecules and platelet-derived microparticles in patients with non-insulin dependent DM after oral administration of $150 \mathrm{mg} /$ day of cilostazol for 4 weeks. ${ }^{27}$ However, they did not measure pro-inflammatory markers or the ABI in their evaluation of the effect of cilostazol. In our study, after 6 months of cilostazol ( $100 \mathrm{mg} /$ day) therapy, the serum sCD40L levels decreased in type 2 DM patients with PAOD but not in those without PAOD. We also found that the TC and LDL levels, not the TG or HDL level, decreased more significantly in the cilostazol group than in the placebo group. The mechanism underlying cilostazol's sCD40L-lowering effect may not involve the previously mentioned lipid effects, so further studies are needed to clarify how it does this.

Kim et al concluded that there was not an additive effect on aspirin-induced anti-platelet activity or decreasing of sCD40L in patients undergoing primary percutaneous coronary intervention 28 Ahn et al also found that cilostazol could not change the serum level of hs-CRP in patients undergoing coronary stenting after already being treated with aspirin and clopidogrel29 They found that cilostazol did not have a clear additive effect in patients with acute coronary syndrome or in patients already taking other antiplatelet drug therapy; less than $30 \%$ of patients had DM. In our study, after excluding patients with a medical history of coronary artery disease, we found a greater reduction in the serum level of sCD40L in patients with type $2 \mathrm{DM}$ complicated with PAOD than in the non-PAOD DM patients treated with cilostazol. This drug may have more significant anti-atherogenic effects in those who have PAOD than in those who do not. In an animal study, the mRNA expression of PPARs was tissue-specific in DM and may be differently affected by cilostazol 30 which could have different antiplatelet and antiinflammatory effects in different tissues. The ischemic change in the lower extremities may alter the tissue response to cilostazol, so we hypothesize that PAOD-related changes in tissue nutrition may contribute to the more apparent reduction in SCD40L in the DM with PAOD group after cilostazol treatment. Thus, further studies are indicated to clarify this hypothesis.

\section{Study Limitations}

According to the Framingham Heart Study, the risk of PAOD can be predicted by age, tobacco use and IR-related metabolic syndromes, including DM, hypercholesterolemia, hypertension and coronary heart disease. However, in our study, the ABI did not correlate with the classical risk factors: BP, lipid profile and HOMA IR. Although office BP may not be a good measure of BP control, many studies, including our own, have not been able to accurately measure home BP or continuously measure $24-\mathrm{h}$ BP, which is a limitation. In the Taiwanese type $2 \mathrm{DM}$ and South Indian populations, a previous study found no association between hypercholesterolemia and the risk of PAOD? There is not an appropriately designed lipid-lowering trial in patients with PAOD, so further evaluation is indicated 31 The avail- 
able lipid profile data we had in this study were insufficient for defining dyslipidemia in the type 2 DM patients. Further evaluation may be needed to determine the level of smalldense LDL or other parameters. Although the HOMA IR model is a widely used tool for evaluating IR, there is a possibility that it could erroneously conclude that patients have poor $\beta$-cell function, especially when they are taking high doses of antidiabetic agents and more than 1 type of oral antidiabetic agent 32 Therefore, either HbA1c or HOMA IR may not be an adequate marker for assessing diabetes control. Fluctuation in the blood glucose levels may cause greater damage to blood vessels 33,34 so continuous glucose monitoring might be considered when doing future studies. In this study, we also found no significant change in the resting $\mathrm{ABI}$ after the 6 months of cilostazol therapy, possible indicating the need for a longer study. ABI $<0.9$ may underestimate the prevalence of PAOD in the general elderly population ${ }^{35}$ Post-exercise ABI evaluation, contrast angiography or magnetic resonance angiography may be more precise.

\section{Conclusion}

PAOD is prevalent in elderly type $2 \mathrm{DM}$ patients. The risk factors of atherogenesis are aging and chronic inflammation, rather than a high $\mathrm{HbA} 1 \mathrm{c}$ level or hypercholesterolemia. Adiponectin level may be a good predictor of PAOD. Cilostazol was able to decrease the levels of hs-CPR and sCD40L, and increase that of adiponecton, and then delay the progression of atherogenesis and chronic inflammation in type 2 diabetics, especially those with PAOD.

\section{Acknowledgment}

This work was supported by a research grant (CMRPG 850511) from Chang Gung Memorial Hospital-Kaohsiung Medical Center, Chang Gung University College of Medicine, Taiwan.

\section{References}

1. Faglia E, Caravaggi C, Marchetti R, Mingardi R, Morabito A, Piaggesi A, et al, SCAR (SCreening for ARteriopathy) study group. Screening for peripheral arterial disease by means of the ankle-brachial index in newly diagnosed Type 2 diabetic patients. Diabet Med 2005; 22: $1310-1314$

2. Feringa HH, Karagiannis SE, Vidakovic R, Elhendy A, Schouten O, Boersma E, et al. Glycemic control, lipid-lowering treatment, and prognosis in diabetic patients with peripheral atherosclerotic disease. Ann Vasc Surg 2007; 21: 780-789.

3. Tseng CH. Prevalence and risk factors of peripheral arterial obstructive disease in Taiwanese type 2 diabetic patients Angiology 2003; 54: $331-338$

4. Tseng $\mathrm{CH}$. Sex difference in the distribution of atherosclerotic risk factors and their association with peripheral arterial disease in Taiwanese type 2 diabetic patients. Circ J 2007; 71: 1131-1136.

5. Nishida M, Moriyama T, Ishii K, Takashima S, Yoshizaki K, Sugita Y, et al. Effects of IL-6, adiponectin, CRP and metabolic syndrome on subclinical atherosclerosis. Clin Chim Acta 2007; 384: 99-104.

6. Iwashima Y, Horio T, Suauki Y, Kihara S, Rakugi H, Kangawa K, et al. Adiponectin and inflammatory markers in peripheral arterial occlusive disease. Atherosclerosis 2006; 188: 384-390.

7. Plutzky J. Inflammation in atherosclerosis and diabetes mellitus. Rev Endocr Metab Disord 2004; 5: 255-259.

8. de Lemos JA, Zirlik A, Schonbeck U, Varo N, Murphy SA, Khera A, et al. Associations between soluble CD40 ligand, atherosclerosis risk factors, and subclinical atherosclerosis: Results from the Dallas Heart Study. Arterioscler Thromb Vasc Biol 2005; 25: 2192-2196.

9. Hirsch AT, Criqui MH, Treat-Jacobson D, Regensteiner JG, Creager MA, Olin JW, et al. Peripheral arterial disease detection, awareness and treatment in primary care. JAMA 2001; 286: 1317-1324.

10. Aso Y, Okumura K, Inoue T, Matsutomo R, Yoshida N, Wakabayashi $\mathrm{S}$, et al. Results of blood inflammatory markers are associated more strongly with toe-brachial index than with ankle-brachial index in patients with type 2 diabetes. Diabetes Care 2004; 27: 1381-1386.

11. Guldiken S, Demir, M, Arikan E, Turgut B, Azcan S, Gerenli M, et al. The levels of circulating markers of atherosclerosis and inflammation in subjects with different degrees of body mass index: Soluble CD40 ligand and high-sensitivity C-reactive protein. Thromb Res 2007; 119: $79-84$.

12. Yamamoto Y, Hirose H, Saito I, Tomita M, Taniyama M, Matsubara $\mathrm{K}$, et al. Correlation of the adipocyte-derived protein adiponectin with insulin resistance index and serum high-density lipoprotein-cholesterol independent of body mass index, in the Japanese population. Clin Sci 2002; 13: 137-142.

13. Dieplinger B, Poelz W, Halmayer M, Mueller T. Hypoadiponectinemia is associated with symptomatic atherosclerotic peripheral arterial disease. Clin Chem Lab Med 2006; 44: 830-833.

14. Chakrabarti S, Varghese S, Vitseva O, Tanriverdi K, Freedman JE. CD40 ligand influences platelet release of reactive oxygen intermediates. Arterioscler Thromb Vasc Biol 2005; 25: 2428-2434.

15. Varo N, Vicent D, Libby P, Nuzzo R, Calle-Pascual AL, Bernal MR, et al. Elevated plasma levels of the atherogenic mediator soluble CD40 ligand in diabetic patients: A novel target of thiazolidinediones. Circulation 2003; 107: 2664-2669.

16. Marx N, Imhof A, Froehlich J, Siam L, Ittner J, Wierse G, et al. Effect of rosiglitazone treatment on soluble CD40L in patients with type 2 diabetes and coronary artery disease. Circulation 2003; 107: 19541957.

17. Lee WJ, Sheu WH, Chen YT, Liu TJ, Liang KW, Ting CT, et al. Circulating CD40 ligand is elevated only in patients with more advanced symptomatic peripheral arterial diseases. Thromb Res 2006; 118: $619-626$.

18. Lee JH, Oh GT, Park SY, Choi JH, Park JG, Kim CD, et al. Cilostazol reduces atherosclerosis by inhibition of superoxide and tumor necrosis factor-alpha formation in low-density lipoprotein receptor-null mice fed high cholesterol. J Pharmacol Exp Ther 2005; 313: 502-509.

19. Agrawal NK, Maiti R, Dash D, Pandey BL. Cilostazol reduces inflammatory burden and oxidative stress in hypertensive type 2 diabetes mellitus patients. Pharmacol Res 2007; 56: 118-123.

20. Hashimoto A, Miyakoda G, Hirose Y, Mori T. Activation of endothelial nitric oxide synthase by cilostazol via a cAMP/protein kinase A- and phosphatidylinositol 3-kinase/Akt-dependent mechanism. Atherosclerosis 2006; 189: 350-357.

21. Hong KW, Kim KY, Shin HK, Lee JH, Choi JM, Kwak YG, et al. Cilostazol prevents tumor necrosis factor-alpha-induced cell death by suppression of phosphatase and tensin homolog deleted from chromosome 10 phosphorylation and activation of Akt/cyclic AMP response element-binding protein phosphorylation. J Pharmacol Exp Ther 2003; 306: 1182-1190.

22. Park SY, Lee JH, Kim KY, Kim EK, Yun SJ, Kim CD, et al. Cilostazol increases 3T3-L1 preadipocyte differentiation with improved glucose uptake associated with activation of peroxisome proliferatoractivated receptor- $\gamma$ transcription (abstract). Atherosclerosis 2008; 201: $258-265$.

23. Douglas JS Jr, Holmes DR Jr, Kereiakes DJ, Grines CL, Block E, Ghazzal ZM, et al. Cilostazol for Restenosis Trial (CREST) Investigators: Coronary stent restenosis in patients treated with cilostazol. Circulation 2005; 112: 2826-2832.

24. Jacoby D, Mohler ER III. Drug treatment of intermittent claudication. Drugs 2004; 64: 1657-1670.

25. Elam MB, Heckman J, Crouse JR, Hunninghake DB, Herd JA, Davidson M, et al. Effect of the novel antiplatelet agent cilostazol on plasma lipoproteins in patients with intermittent claudication. Arterioscler Thromb Vasc Biol 1998; 18: 1942-1947.

26. Ikewaki K, Mochizuki K, Iwasaki M, Nishide R, Mochizuki S, Tada N. Cilostazol, a potent phosphodiesterase type III inhibitor, selectively increases antiatherogenic high-density lipoprotein subclass LpA-I and improves postprandial lipemia in patients with type 2 diabetes mellitus. Metabolism 2002; 51: 1348-1354.

27. Nomura S, Inami N, Iwasaka T, Liu Y. Platelet activation markers, microparticles and soluble adhesion molecules are elevated in patients with arteriosclerosis obliterans: Therapeutic effects by cilostazol and potentiation by dipyridamole. Platelets 2004; 15: 167-172.

28. Kim JY, Lee K, Shin M, Ahn M, Choe H, Yoo BS, et al Cilostazol could ameliorate platelet responsiveness to clopidogrel in patients undergoing primary percutaneous coronary intervention. Circ J 2007; 71: $1867-1872$

29. Ahn JC, Song WH, Kwon JA, Park CG, Seo HA, Oh DJ, et al. Effects of cilostazol on platelet activation in coronary stenting patients who already treated with aspirin and clopidogrel. Korean J Intern Med 2004; 19: 230-236.

30. Wang F, Gao L, Gong B, Hu J, Li M, Guan Q, et al. Tissue-specific expression of PPAR mRNAs in diabetic rats and divergent effects of 
cilostazol. Can J Physiol Pharmacol 2008; 86: 465-471.

31. Kroger K. Dyslipoproteinemia and peripheral arterial occlusive disease. Angiology 2004; 55: 135-138.

32. Wallace TM, Levy JC, Matthews DR. Use and abuse of HOMA modeling. Diabetes Care 2004; 27: 1487-1495.

33. Mita T, Otsuka A, Azuma K, Uchida T, Ogihara T, Fujitani Y, et al. Swings in blood glucose levels accelerate atherogenesis in apolipoprotein E-deficient mice. Biochem Biophys Res Commun 2007; 358: $679-685$.
34. Watada H, Azuma K, Kawamori R. Glucose fluctuation on the progression of diabetic microangiopathy: New findings from monocyte adhesion to endothelial cells. Diabetes Res Clin Pract 2007; 77: S58-S61.

35. Wikström J, Hansen T, Johansson L, Lind L, Ahlström H. Ankle brachial index $<0.9$ underestimates the prevalence of peripheral artery occlusive disease assessed with whole-body magnetic resonance angiography in the elderly. Acta Radiol 2008; 49: 143-149. 